\title{
Assessment of Effect of COVID 19 Pandemic on the Utilization of Maternal Newborn Child Health and Nutrition Services in Somali Region of Ethiopia
}

\author{
Olusola Oladeji'1), Bibilola Oladeji²), Abdifatah Elmi Farah'), \\ Yusuf Mohammed Ali3), Mohamed Ayanle3) \\ 1)UNICEF Somali Field Office, Ethiopia \\ 2) College of Medicine, University of Ibadan, Nigeria \\ 3)Somali Regional Health Bureau, Ethiopia
}

\section{ABSTRACT}

Background: Somali Region of Ethiopia recorded the first confirmed case of SARS-CoV2 (COVID 19) pandemic on $26^{\text {th }}$ April 2020. The study aimed to assess the effect of the pandemic on the utilization of maternal newborn, child and nutrition health services.

Subjects and Method: This was a retrospective chart review of monthly DHIS database of health facilities in Farfan zone of Somali Region and test of association using $t$ test was used to compare the mean reduction in utilization of maternal and child health services three months before (January - March 2020) and three months during the pandemic (April 2020 to June 2020) at $p$ value set at significant level of $5 \%$. The outcome measure was the utilization of maternal newborn child health and services. Results: The mean reductions in OPD per capita for children under five, children who received first dose of pentavalent vaccines and pregnant women who received first ANC before and during the pandemic was 14.26\%, $\mathrm{t}=1.07$; $95 \% \mathrm{CI}=283.17$ to $725.17 ; \mathrm{p}=0.325) ; 12.51 \%$, $\mathrm{t}=0.74 ; 95 \% \mathrm{CI}=1439.33$ to $2697.31 ; \mathrm{p}=0.489$ ) and $14.43 \%, t=0.49 ; 95 \% \quad C I=2363.33$ to 3543.41; $\mathrm{p}=0.642$ ) respectively, while the mean reduction in skilled birth deliveries conducted at the health facilities was $21.4 \%, \mathrm{t}=0.97 ; 95 \% \mathrm{CI}=$ 319.26 to $736.16 ; p=0.371$ ).

Conclusion: The study provided early effects of COVID 19 on health and nutrition services to health and nutrition services. This study indicated that indirect health service effects are substantial and highlights the importance of maintaining routine essential health and nutrition service delivery and the need to explore innovative ways of delivering both preventive and curative essential services.

Keywords: COVID 19, pandemic, maternal newborn and child health and nutrition, utilization, essential services

\section{Correspondence:}

Olusola Oladeji. UNICEF Somali Field Office, Ethiopia. Email: ooladeji@unicef.org.

Cite this as:

Oladeji O, Oladeji B, Elmi Farah A, Ali YM, Ayanle M (2020). Assessment of Effect of COVID 19 Pandemic on the Utilization of Maternal Newborn and Child Health Services in Somali Region of Ethiopia. J Epidemiol Public Health. 05(04): 458-469. https://doi.org/10.26911/jepublichealth.2020.05.04.08.

\section{(c) (i) (2) Journal of Epidemiology and Public Healthis licensed under a Creative Commons}

Journal of Epidemiology and Public Healthis licensed under a Creat
Attribution-NonCommercial-ShareAlike 4.o International License.

\section{BACKGROUND}

Ethiopia has made great efforts in recent years to improve maternal, newborn, and child health (MNCH) outcomes with the implementation of the country's healthsector transformation plan and other strategic initiatives that have driven a steady decline in maternal, newborn, infant, child and under five mortality (United Nations, 2015). However, there are still wide variations in these indicators at the subnational level. Somali Region which is one of Ethiopia's four Developing Regional States (DRS) and the second largest region in Ethiopia in 
terms of land mass with population of over 6 million people, predominantly pastoralists (85\%), with most people living in hard to reach/remote areas faces developmental inequities(Federal Ministry of Health of Ethiopia, 2010).The region has shown less improvement in key health outcomes compared to the national average, the 2019 Mini DHS reports that the region has the lowest percentage of fully vaccinated children, with only18.2\% having received all basic vaccinations, and $48.8 \%$ had received no vaccinations at all compared to national average of $43.1 \%$ and $19.2 \%$ respectively while the proportion of pregnant women who received at least four antenatal care services (ANC4) and delivered by skilled birth attendant is $11.1 \%$ and $26 \%$ compared to national average of $43 \%$ and $49.8 \%$ respectively( Ethiopia Central Statistical Agency and ICF, 2019).

The health system in the region is reportedly weak with limited number of health facilities, poor infrastructure, disproportionate mix of health professionals. The health workers density ratio $1.6 \mathrm{per}$ 1,000 population and the workforce is not proportionately distributed with health facilities in remote areas poorly staffed. More than $60 \%$ of the population walks for more than one hour to reach the nearest health facilities regardless of their functionality status (Somali Regional Health Bureau, 2020).

Ethiopia recorded the first confirmed case of SARS-CoV-2 (COVID 19) pandemic on $13^{\text {th }}$ March 2020 and first case in Somali Region was confirmed on $26^{\text {th }}$ April 2020 among returnees from Somalia who were quarantined in Jijiga town of Fafan zone. As at $30^{\text {th }}$ June 2020, a total of 437 cases have been reported in the region. In order to ensure effective containment of the pandemic among susceptible community population in the region, the attention of the health sector was diverted towards prevention of the spread and response to COVID-19. Even though a large proportion of health workers were engaged in Covid-19 response, efforts were made to ensure routine essential health services were not completely interrupted.

The analysis the 2014 outbreak of Ebola virus in West Africa showed that the indirect effects of the outbreak were more severe than the outbreak itself especially on maternal newborn and child health and nutrition (Elston et al., 2017). In the ongoing pandemic the mortality rates for COVID-19 appear to be low in children and in women of reproductive age, however they are likely to be disproportionately affected by the disruption of routine health and nutrition services especially children in the poorest neighbourhoods, and for those in already disadvantaged or vulnerable situations like Somali Region of Ethiopia with weak health systems and the children deprived in three or more dimensions (WHO, 2020; United Nations, 2020; CSA and UNICEF Ethiopia (2018) .

This study aimed to assess the effect of the COVID pandemic on the utilization of routine maternal newborn and child health and nutrition services in already weak health system in the region and explore opportunities to ensure continuation of essential high impact health and nutrition services.

\section{SUBJECTS AND METHOD}

\section{Study Design}

This was a retrospective chart review of monthly District Health Information System (DHIS) on the utilization of maternal newborn and child health and nutrition services from the database of health facilities in Fafan zone of Somali Region. The chart reviewed was reported between April 2019 and June 2020 in the health facilities in 
Fafan zone accessed through the Regional DHIS database

\section{Population and Sample}

The study was conducted in Farfan zone of the of Somali region of Ethiopia and selected using convenient sampling technique being the epic centre of the COVID 19 pandemic in the region with more than $70 \%$ of the confirmed cases in the region. The zone has estimated population of 1,250,069; 127 health posts, 27 health centers and one regional and one referral hospital.

\section{Study Variable}

The study variable was the utilization of maternal, newborn and child health and nutrition services before the pandemic and during the pandemic. The study instrument used to collect the data was the District Health Information System (DHIS) database.

\section{Operational Definition of Variables}

The study variable was the utilization of maternal, newborn and child health and nutrition services before the pandemic and during the pandemic which was evaluated by assessing: (1) pregnant women who received first Antenatal care visit (ANC 1), facility skilled birth delivery, children under one provided with $1^{\text {st }}$ and $3^{\text {rd }}$ dose of pentavalent vaccines (Penta 1 and Penta 3), children treated for malnutrition at the Outpatient therapeutic feeding program (OTP) and, Outpatient visits per capita which is the number of outpatient department visit per 10,000 population.

\section{Data Analysis}

The data on utilization of maternal and child health services were extracted from the regional DHIS database managed by the Regional HMIS/Planning department. The data were entered into a Microsoft Excel and analyzed using SPSS version 21. Descriptive data is presented in graph and univariate analysis was done by generating frequencies of the variables and test of association was done using paired t test to compare the mean reduction in utilization of maternal and child health services three months before the pandemic (January 2020 to March 2020) and three months during the pandemic (April 2020 to June 2020) and changes in maternal and child health services in the health facilities (April 2019 to June 2019) and (April 2020 June 2020) at $\mathrm{p}$ value was set at significant level of $5 \%$.The outcome measure was the utilization of maternal and child health services which was evaluated by assessing: (1) pregnant women who received first Antenatal care visit(ANC 1), facility skilled birth delivery, children under one provided with $1^{\text {st }}$ and $3^{\text {rd }}$ dose of pentavalent vaccines (Penta 1 and Penta 3), children treated for malnutrition at the outpatient therapeutic feeding program (OTP) and, outpatient visits per capita which is the number of outpatient department visit per 10,000 population.

\section{RESULTS \\ A. Utilization of OPD and Nutrition (OTP) services}

Table 1 shows the changes in the outpatient visit per capita (OPD per capita) among children under 5 treated for common ailments at the health facilities and children 6 month-5 years with severe acute malnutrition treated at the outpatient therapeutic feeding program (OTP)3 months before the pandemic (January 2020 to March 2020) and 3 months during the pandemic (April 2020 to June 2020).

The mean OPD per capital before the pandemic (mean $=1,549.75 ; \mathrm{SD}=118.16$ ) compared to mean $=1,328.75 ; \mathrm{SD}=85.71$ ) during the pandemic which shows a mean reduction of $14.26 \%$. This difference is however not statistically significant $(\mathrm{t}=1.07$; 95\% CI= 283.17 to 725.17; $\mathrm{p}=0.325$ ).

The mean number of children 6 months till 5years treated for severe acute 
malnutrition at the OTP before the pandemic (mean $=30.25 ; \mathrm{SD}=4.25$ ) compared to mean $=27.0 ; \mathrm{SD}=2.05$ ) during the pandemic which shows a mean reduction of
10.7\%. This difference also not statistically significant $(\mathrm{t}=0.76 ; 95 \% \mathrm{CI}=10.34$ to 16.84 ; $\mathrm{p}=0.502)$

Table 1. Service utilization for children under 5 treated at the OPD and nutrition clinic in the health facilities before the pandemic (January-March 2020) during the pandemic (April 2020- June 2020)

\begin{tabular}{|c|c|c|c|c|c|c|}
\hline \multirow{2}{*}{ Variables } & \multirow{2}{*}{ Mean } & \multirow{2}{*}{ SD } & \multirow{2}{*}{ T -test } & \multicolumn{2}{|c|}{$95 \%$ CI } & \multirow[b]{2}{*}{$\mathbf{p}$} \\
\hline & & & & Lower Limit & Upper Limit & \\
\hline \multicolumn{7}{|l|}{$\begin{array}{l}\text { Outpatient visits } \\
\text { per capita }\end{array}$} \\
\hline $\begin{array}{l}\text { Before pandemic } \\
\text { (January 2020-March } \\
\text { 2020) }\end{array}$ & 1549.75 & 118.16 & 1.072 & 283.17 & 725.17 & 0.325 \\
\hline $\begin{array}{l}\text { During pandemic } \\
\text { (April 2020 - June } \\
\text { 2020) }\end{array}$ & 1328.74 & 85.71 & & & & \\
\hline $\begin{array}{l}\text { Children treated } \\
\text { for Severe acute } \\
\text { malnutrition }\end{array}$ & & & & & & \\
\hline $\begin{array}{l}\text { Before pandemic } \\
\text { (January 2020-March } \\
\text { 2020) }\end{array}$ & 30.25 & 4.25 & 0.76 & 10.34 & 16.84 & 0.502 \\
\hline $\begin{array}{l}\text { During pandemic } \\
\text { (April 2020 - June } \\
\text { 2020) }\end{array}$ & 27.0 & 2.05 & & & & \\
\hline
\end{tabular}

Figure 1 shows the number of children under 5 who were treated for diarrhea, acute respiratory infection (ARI) and severe acute malnutrition (SAM) in the health facilities between January and June 2020. This shows the progressive decline in the number of cases treated from April 2020 to June 2020 during the outbreak compared to cases treated before the pandemic.

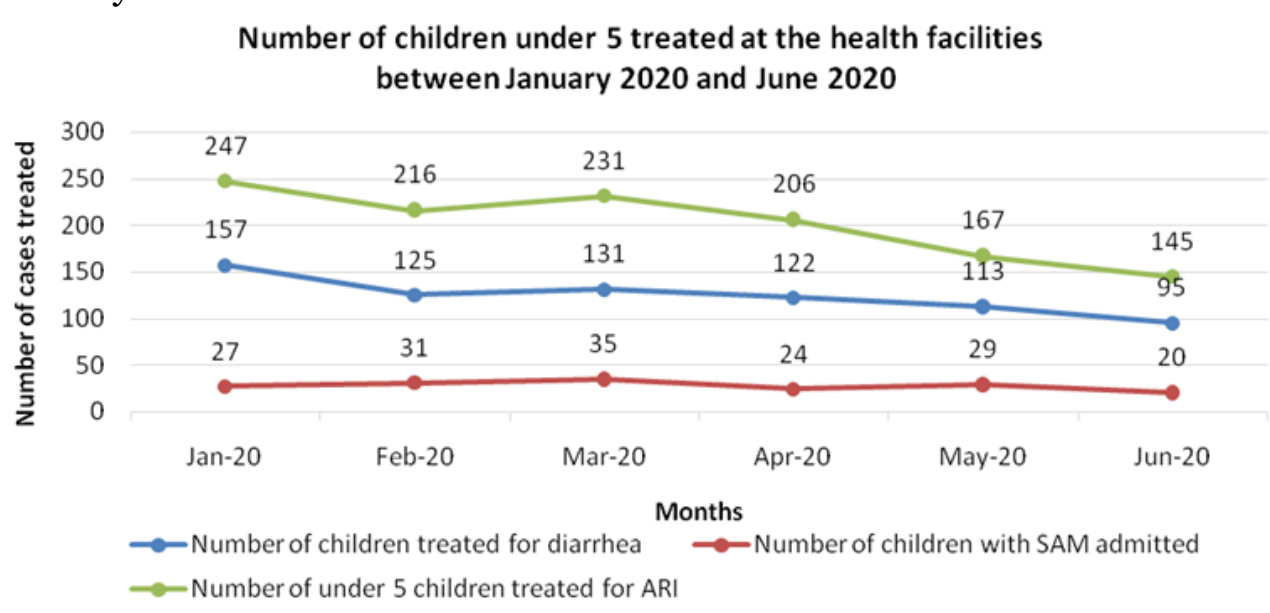

Figure 1. Children under 5 years treated at the health facilities between January 2020 and June 2020

B. Utilization of Maternal and newborn health services
Table 2 shows the changes in the utilization of maternal health services by pregnant 
women in the health facilities 3 months before the pandemic (January 2000- March 2020) and 3 months during the pandemic (March 2020- June 2020).

The mean number of pregnant women who received first Antenatal Care visit (ANC1) before the pandemic (mean= 4087.75; $\mathrm{SD}=544.25)$ compared to mean= $3497.75 ; \mathrm{SD}=765.35)$ during the pandemic which shows a mean reduction of $14.43 \%$. This difference is however not statistically

Table 2. Maternal and newborn health services in the health facilities before the pandemic (January-March 2020) and during the pandemic (April-June 2020)

\begin{tabular}{|c|c|c|c|c|c|c|}
\hline \multirow{2}{*}{ Variables } & \multirow{2}{*}{ Mean } & \multirow{2}{*}{ SD } & \multirow{2}{*}{$\begin{array}{c}\mathbf{T}- \\
\text { test }\end{array}$} & \multicolumn{2}{|c|}{$95 \%$ CI } & \multirow{2}{*}{$\mathbf{p}$} \\
\hline & & & & Lower Limit & Upper Limit & \\
\hline $\begin{array}{l}\text { Pregnant women } \\
\text { who received } \\
\text { ANC1 }\end{array}$ & & & & & & \\
\hline $\begin{array}{l}\text { Before pandemic } \\
\text { (January 2020- } \\
\text { March 2020) }\end{array}$ & 4087.75 & 544.25 & 0.49 & 2363.33 & 3543.41 & 0.642 \\
\hline $\begin{array}{l}\text { During pandemic } \\
\text { (April } 2020 \text { - June } \\
\text { 2020) }\end{array}$ & 3497.75 & 765.35 & & & & \\
\hline $\begin{array}{l}\text { Deliveries by } \\
\text { skilled birth } \\
\text { attendants }\end{array}$ & & & & & & \\
\hline $\begin{array}{l}\text { Before pandemic } \\
\text { (January 2020- } \\
\text { March 2020) }\end{array}$ & 1440.12 & 147.42 & 0.97 & 319.26 & 736.16 & 0.371 \\
\hline $\begin{array}{l}\text { During pandemic } \\
\text { (April } 2020 \text { - June } \\
\text { 2020) }\end{array}$ & 1131.75 & 40.52 & & & & \\
\hline
\end{tabular}

Table 3 shows the changes in the utilization of maternal health services by pregnant women in the health facilities similar months April - June 2019 when there was no pandemic and during the pandemic (April - June 2020).

The mean number of pregnant women who received first Antenatal Care visit( $\mathrm{ANC1}$ ) within three months in the same period in 2019 when there was no pandemic (mean $=3107.33 ; \mathrm{SD}=600.44)$ compared to mean $=3497.75 ; \mathrm{SD}=660.25$ ) during the pandemic in 2020 which shows a mean increase of $14.43 \%$. This difference is significant $(\mathrm{t}=0.49 ; 95 \% \mathrm{CI}=2363.33$ to $3543.41 ; \mathrm{p}=0.642)$.

The mean number of skilled birth deliveries conducted at the health facilities before the pandemic was 1440.12; $\mathrm{SD}=$ 147.42) compared to mean $=1131.75 ; \mathrm{SD}=$ 40.52 during the pandemic which shows a mean reduction of $21.4 \%$. This difference is however not statistically significant $(\mathrm{t}=0.97$; $95 \% \mathrm{CI}=319.26$ to $736.16 ; \mathrm{p}=0.371$ ).

however not statistically significant $(\mathrm{t}=$ $0.24 ; 95 \% \mathrm{CI}=4317.17$ to $3536.33 ; \mathrm{p}=$ o.816).

The mean number of skilled birth deliveries conducted at the health facilities within three months in the same period in 2019 when there was no pandemic (mean= 1002.13; $\mathrm{SD}=103.27)$ compared to (mean= 1131.75; $\mathrm{SD}=94.83$ ) during the pandemic in 2020 which shows a mean increase of 12.93\%. This difference is however not statistically significant $(\mathrm{t}=0.68 ; 95 \% \mathrm{CI}=$ 338.03 to 597.27 ; $\mathrm{p}=0.523)$. 
Table 3. Maternal and newborn health services in the health facilities (April - June 2019) and (April 2020- June 2020)

\begin{tabular}{|c|c|c|c|c|c|c|}
\hline \multirow[b]{2}{*}{ Variables } & \multirow[b]{2}{*}{ Mean } & \multirow[b]{2}{*}{ SD } & \multirow[b]{2}{*}{ T -test } & \multicolumn{2}{|c|}{$95 \% \mathrm{CI}$} & \multirow[b]{2}{*}{$\mathbf{p}$} \\
\hline & & & & $\begin{array}{l}\text { Lower } \\
\text { Limit }\end{array}$ & $\begin{array}{l}\text { Upper } \\
\text { Limit }\end{array}$ & \\
\hline $\begin{array}{l}\text { Pregnant women who } \\
\text { received ANC1 } \\
\text { April -June } 2019 \\
\text { April -June } 2020 \\
\text { Deliveries by Skilled } \\
\text { birth attendants }\end{array}$ & $\begin{array}{l}3107.33 \\
3497.75\end{array}$ & $\begin{array}{l}600.44 \\
660.25\end{array}$ & 0.24 & 3536.33 & 4317.17 & 0.816 \\
\hline $\begin{array}{l}\text { April -June } 2019 \\
\text { April -June } 2020\end{array}$ & $\begin{array}{c}1002.13 \\
103.27 \\
\end{array}$ & $\begin{array}{c}1131.75 \\
94.83 \\
\end{array}$ & 0.68 & 338.03 & 597.27 & 0.523 \\
\hline
\end{tabular}

\section{Utilization of Immunization services}

Table 4 shows the changes in the utilization of immunization services among children under one in the health facilities 3 months before the pandemic (January-March 2020) and 3 months during the pandemic (April 2020- June 2020).

The mean number of children who received first dose of pentavalent vaccine (Penta 1) before the pandemic (mean= 4227.25; $\mathrm{SD}=178.05$ ) compared to (mean= 3698.23; $\mathrm{SD}=457.26$ ) during the pandemic which shows a mean reduction of $12.51 \%$. This difference is however not statistically significant $(t=0.74 ; 95 \% \mathrm{CI}=1439.33$ to 2697.31; $\mathrm{p}=0.489)$.

The mean number of children who received third dose of pentavalent vaccine (Penta 3) before the pandemic (mean= 3589.5; $\mathrm{SD}=141.21)$ compared to mean= 3097.5; $\mathrm{SD}=127.83$ ) during the pandemic which shows a mean reduction of $13.7 \%$. This difference is however not statistically significant $(t=0.72 ; 95 \% \mathrm{CI}=1175.64$ to 2159.61; $\mathrm{p}=0.497$ ).

The dropout rate between children who received the pentavalent vaccines is 15.08\% before pandemic and $16.25 \%$ during the pandemic.

Table 4. Immunization service for children before the pandemic (January -March 2020) and during the pandemic (April - June 2020)

\begin{tabular}{|c|c|c|c|c|c|c|}
\hline \multirow[b]{2}{*}{ Variables } & \multirow[b]{2}{*}{ Mean } & \multirow[b]{2}{*}{ SD } & \multirow[b]{2}{*}{ T -test } & \multicolumn{2}{|c|}{$95 \%$ CI } & \multirow[b]{2}{*}{$\mathbf{p}$} \\
\hline & & & & $\begin{array}{l}\text { Lower } \\
\text { Limit }\end{array}$ & $\begin{array}{l}\text { Upper } \\
\text { Limit }\end{array}$ & \\
\hline \multicolumn{7}{|l|}{$\begin{array}{l}\text { Children under one who } \\
\text { received Penta } 1 \text { vaccine }\end{array}$} \\
\hline $\begin{array}{l}\text { Before pandemic (January - } \\
\text { March 2020) }\end{array}$ & 4227.25 & 178.05 & 0.74 & 1439.33 & $2697 \cdot 31$ & 0.489 \\
\hline $\begin{array}{l}\text { During pandemic (April- June } \\
\text { 2020) }\end{array}$ & 3698.23 & 457.26 & & & & \\
\hline \multicolumn{7}{|l|}{$\begin{array}{l}\text { Children under one who } \\
\text { received Penta3 vaccine }\end{array}$} \\
\hline $\begin{array}{l}\text { Before pandemic (January- } \\
\text { March 2020) }\end{array}$ & 3589.5 & 141.21 & 0.72 & 1175.64 & 2159.61 & 0.497 \\
\hline $\begin{array}{l}\text { During pandemic (April- June } \\
\text { 2020) }\end{array}$ & 3097.5 & 127.83 & & & & \\
\hline
\end{tabular}


Table 5 shows the changes in the utilization of immunization services among children under one in the health facilities similar months April 2019- June 2019 when there was no pandemic and during the pandemic (April- June 2020).

The mean number of children who received first dose of pentavalent vaccine (Penta 1) within four months in the same period in 2019 when there was no pandemic (mean= 4328.87; $\mathrm{SD}=268.42)$ compared to (mean $=3698.23 ; \mathrm{SD}=304.13)$ during the pandemic which shows a mean reduction of 14.57\%. This difference is however not statistically significant $(\mathrm{t}=0.75 ; 95 \% \mathrm{CI}=$ 1424.09 to 26684.19; $\mathrm{p}=0.4813$ ).

Table 5. Immunization service for children in the health facilities (April - June 2019) and (April - June 2o20)

\begin{tabular}{|c|c|c|c|c|c|c|}
\hline \multirow[b]{2}{*}{ Variables } & \multirow[b]{2}{*}{ Mean } & \multirow[b]{2}{*}{ SD } & \multirow[b]{2}{*}{ T -test } & \multicolumn{2}{|c|}{$95 \% \mathrm{CI}$} & \multirow[b]{2}{*}{$\mathbf{p}$} \\
\hline & & & & $\begin{array}{l}\text { Lower } \\
\text { Limit }\end{array}$ & $\begin{array}{l}\text { Upper } \\
\text { Limit }\end{array}$ & \\
\hline \multicolumn{7}{|l|}{$\begin{array}{l}\text { Children under one who } \\
\text { received Penta } 1 \text { vaccine }\end{array}$} \\
\hline April -June 2019 & 4328.87 & 268.42 & 0.75 & 1424.09 & 2684.19 & 0.48 \\
\hline April -June 2020 & 3698.23 & 304.13 & & & & \\
\hline \multicolumn{7}{|l|}{$\begin{array}{l}\text { Children under one who } \\
\text { received Penta } 3 \text { vaccine }\end{array}$} \\
\hline April -June 2019 & 3648.17 & 196.26 & 0.76 & 1231.27 & 2322.41 & 0.497 \\
\hline April -June 2020 & 3097.5 & 228.53 & & & & \\
\hline
\end{tabular}

The mean number of children who received third dose of pentavalent vaccine (Penta 3) within three months in the same period in 2019 when there was no pandemic (mean $=3648.17 ; \mathrm{SD}=196.26)$ compared to (mean $=3097.5 ; \mathrm{SD}=228.53$ ) during the pandemic which shows a mean reduction of $15.1 \%$. This difference is however not statistically significant $(\mathrm{t}=0.76 ; 95 \% \mathrm{CI}=$ 1231.27 to 2322.41; $\mathrm{p}=0.4782$ ).

The dropout rate between children who received the pentavalent vaccines is 15.72\% before pandemic and $16.25 \%$ during the pandemic.

\section{DISCUSSION}

This study presents the trends in utilisation of maternal,newborn and child health and nutrition services before and during COVID19 pandemic and shows decrease in all uptake of maternal and child health services after the onset of the outbreak. The findings are similar to studies done to evaluate of the indirect health impacts of the 2014 to 2016 Ebola epidemic in West Africa on maternal newborn and child health and nutrition services (Elston et al., 2015; Bolkan et al., 2014; Sochas et al., 2017; Lori et al., 2015) and early estimate on the indirect impact of
COVID 19 on maternal and child health (Roberton et al., 2020).

Our study shows that there was reduction in the utilization of antenatal care services and health facility delivery by skilled birth attendants during the pandemic which is similar to findings in a studies Sierra Leone, Liberia and a systematic review of Ebola in west Africa which reported decrease in facility deliveries, and in the volume of antenatal and postnatal care visits during with associated significant adverse effects on maternal and newborn health (Elston et al., 2015; Bolkan et al., 2014; 
Sochas et al., 2017; Lori et al., 2015; Ribacke et al., 2016).

The Sierra Leone study reported during the outbreak, antenatal care coverage decreased by 22 percentage points similar to our study, declines in the coverage of family planning (6 percentage points), facility delivery ( 8 percentage points) which is much lower than our finding, and postnatal care (13 percentage points) during the outbreak while the study in Liberia reported a decline of $14 \%$ in antenatal care coverage, the same decline reported in our study and 9\% in facility delivery (Sochas et al., 2017; Lori et al., 2015).

Another study in Sierra Leone which examined the adverse effects of the Ebola outbreak on maternal and newborn health reported 3opercent rise in maternal death and 2percent rise in incidence of still birth during the outbreak, though this was not assessed in our study (VSO International,2015).

An estimate done on the indirect effect of the pandemic on maternal and child mortality in low income and middle income countries like Ethiopia shows that if routine health care is disrupted the increase in child and maternal deaths will be devastating and reported a possible increase of 9.8-44.7 percent in under- 5 child deaths per month, and an 8.3-38.6 percent increase in maternal deaths per month over a period of 6 months if no tangible actions are taken (Roberton et al., 2020). A prospective observational study on the effect of the COVID-19 pandemic response on intrapartum care, stillbirth, and neonatal mortality outcomes in Nepal reported that number of institutional births decreased by $52 \cdot 4 \%$ which is higher than our finding, while institutional stillbirth rate increased from 14 per 1000 total births to 21 per 1000 total births before and during lockdown and women in relatively disadvantaged ethnic groups were found to be affected more than those in more advantaged groups, indicating a widening equity gap due to COVID-19 ( Ashish etal., 2020)

Our study also reported reduction in uptake of preventive and curative child health in the health facilities during the pandemic, this is similar to the reported significant drop in utilization of children's health services, especially in terms of vaccination coverage in studies conducted in Guinea and Liberia on the effect of Ebola in the west Africa (Ribacke et al., 2016; Barden-O'Fallon et al., 2015; Wesseh et al., 2017). The study in guinea showed a decrease in first and third doses of pentavalent vaccines of 18 percent and 32 percent respectively while the study in Liberia reported drop in the proportion of children under 1 who were fully immunized from 73 percent before the epidemic, to 36 percent during the epidemic, and recovered only partially to 53 percent post outbreak. Similar to our finding in this study, significant decline in the number median numbers of outpatient visits with $31 \%$ reduction in the median number of outpatient clients was reported during the outbreak with fewer cases of diarrhoea and Acute respiratory infection which were attributed to parents' reluctance to bring children to health facilities out of fear of contracting Ebola (Barden-O'Fallon et al.,2015).

The reduction in the number of diarrhoea case and Acute respiratory infection our study can also be due to the improved hand washing practices as a result of the intensive risk communication and community engagement on COVID being implemented.

Our study shows decline in children treated for severe acute malnutrition during the pandemic, this is similar to study in one Ebola-affected district in Sierra Leone which reported fewer cases of childhood severe 
acute malnutrition diagnosed during the outbreak but increased from 1.5 percent before the outbreak to 3.5 percent after the outbreak (Kamara et al., 2017).

The reduction in utilization of health services is likely due to both access and uptake of health services, with some health workers also engaged in COVID 19 activities in the communities that take them away from the facilities especially in the health posts with only one health worker. The low service uptake may be due to the community perception of and fear of contracting COVID 19 at the health facility oras a result of misinformation on whether health facilities were open and providing services during the outbreak. However, unlike the closure of health facilities reported in most countries during the Ebola and ongoing COVID pandemic, the review of the health facility database in our study shows that no health facility was closed as a result of the pandemic.

In our study we also analyzed the difference in the mean utilization of maternal and health service between the same months on April 2019 - June 2019 a year before the pandemic and the same period April 2019 -June 2020 during the pandemic and found out that there was increase in the utilization of ANC and delivery services during the pandemic but reduction in the mean number of children who were vaccinated during the pandemic. No study so far to our knowledge has compared the utilization of service a year or more before the COVID 19 pandemic and during the pandemic. However the only study in Liberia among various studies that evaluated the impact of the 2014 to 2016 Ebola outbreak compared the utilization of health services over a period of four year before the outbreak showed a slight reduction in the utilization of ANC and delivery services between years before the pandemic and during the pandemic, however the reduction in the utilization of immunization service in the same period was very high and significant (Wagenaar et al., 2018). It seems utilization of service for children is more affected than for mothers. This is supported by a study in Sierra Leone which assessed the perceptions of the risk for Ebola and health facility use among health workers and pregnant and lactating women, which reported that among the women interviewed, deliveries in health facilities were perceived to be less affected by the Ebola outbreak compared with immunization care (Dynes et al., 2014). A focus group participants in another study during Ebola stated they stopped having their children immunized for fear of the 'needles injecting Ebola' and had believed the weighing scales would give their children Ebola and claimed that rumors in their communities had created a societal pressure to refrain from bringing children to the clinics (Elston et al., 2015).

Our study shows reduction in the mean utilization of all services during COVID compared to pre COVID 19 even though not significant. The study looked at 3 months when the outbreak started and may be too early to detect any significant changes. In addition, there was no report of locked down or closure of health facilities unlike what was reported in most of the studies that assessed indirect effect of Ebola or COVID 19 on utilization of health service which reported significant difference in the reduction of service utilization. This is because based on the learning from the experience from Ebola and other countries which reported earlier the outbreak on COVID 19, the Regional Health Bureau in line with the national guideline established a taskforce committee to track and monitor access and utilization of routine essential health services which ensured that even 
though health workers were involved in COVID preparedness and response efforts, routine essential services continued and any patient who visited health facilities were likely to be attended to

(Federal Ministry of Health of Ethiopia , 2020). It may be important to review the utilization of services again in the next few months into the pandemic to see if the differences in the utilization between period before the pandemic and during the will be significant

Limitation of the study: This study is based on clinic records and thus subject to the limitations associated with studies utilizing routine data affected by the quality of the data used. While the DHIS2 data is reported from a large number of facilities, the reliability of the data has not been independently verified, and it is unclear if data was being collected and reported accurately.

Policy Implication: This study corroborates finding from other studies on early estimates of the indirect effects of the COVID-19 pandemic and Ebola Outbreak in West Africa 2014-2016 on maternal and child mortality especially in low income countries and the actions needed including policy shift in order to reduce the impact of the pandemic on mothers and children.

Somali region a predominantly pastoralists community with wide geographical spread currently operates a two-level primary health care service delivery called primary health care unit (PHCU) which is a health centre linked to 5 health posts. There is need to review this and adopt a three-level service delivery (health centre, health post and community/village level) to strengthen PHCU service and link community and health facilities. Community/village level service will include sharing/shifting some of the tasks being implemented by health extension workers in the health posts such as health promotion, disease prevention, infection prevention and control, community mobilization and basic home care services. The community volunteers at the village level will also be trained to provide community-based nutrition including infant and child feeding practices and community based maternal and newborn care service and tracking of defaulters. This will strengthen the community health system and linkage with the health facilities and help ensure continuous access to basic essential health and nutrition services during outbreaks. The engagement of the community health volunteers will also help to reduce the caseload of the limited number of healthcare professionals through task shifting and fill the critical gaps in the human resource for health and ensure access to quality equitable and affordable health care services. This will also give opportunity to the health workers in the health facilities to focus and address more complex health services especially during outbreaks and promote effectiveness and efficiency.

In addition, outreach modality using house-to-house delivery of services or a mini-campaign by health facility staff and community volunteers to rapidly scale up access to basic health services like immunization, Vitamin A supplementation, Iron Fe supplementation to pregnant women can be explored so as to increase coverage of maternal and child health and nutrition indicators.

The study provides early effects of COVID 19 on health and nutrition services and can help guide policy development on health system strengthening and resilience for with standing future outbreaks. This study indicates that indirect health service effects are substantial and highlights the importance of support to maintain routine 
health service delivery and the need to explore innovative ways of delivering both preventive and curative essential service.

\section{AUTHOR CONTRIBUTION}

Olusola Oladeji conceived the documentation, analyzed the data, developed the first draft and finalized the manuscript. All the authors read, reviewed, and approved the final draft of the manuscript.

\section{CONFLICT OF INTEREST}

The findings of this study and recommendations arising from this study are the sole responsibility of the authors and do not represent the position of the organizations they work for. Authors have declared that no competing interests exist.

\section{FUNDING AND SPONSORSHIP}

The authors received no financial support for the research, authorship, and/or publication of this article.

\section{ACKNOWLEDGEMENT}

The authors would like to thank Mohammed Diriye of the Somali Regional Health Bureau who provided the health facilities data from the DHIS2 for the analysis.

\section{REFERENCE}

Ashish KC, Gurung R, Kinney MV, Avinash $\mathrm{K}$, Moinuddin M, Basnet O, Paudel P, et al. (2020). Effect of the COVID-19 pandemic response on intrapartum care, stillbirth, and neonatal mortality outcomes in Nepal: a prospective observational study. Lancet Glob Health. https://doi.org/10.1016/ S2214-109X (20)30345-4.

Barden-O'Fallon J, Barry MA, Brodish P, Hazerjian J (2015). Rapid Assessment of Ebola-Related Implications for Reproductive, Maternal, Newborn and Child Health Service Delivery and
Utilization in Guinea. PLOS Currents Outbreaks, Edition 1. doi: 10.1371/currents.outbreaks.obobao6oogddo9 1bc39ddb3c6d7bo82

Bolkan HA, Bash-Taqi DA, Samai M, Gerdin M, von Schreeb J (2014). Ebola and indirect effect on health services functions in Sierra Leone. PLOS Curr, 6. Edition 1. doi:10.1371/currents.outbreaks.0307d588df619f9c9447f8e ad5b72b2d.

Brolin Ribacke KJ, Saulnier D, Eriksson A, von Schreeb J (2016). Effects of the West Africa Ebola virus disease on health-care utilization-a systematic review. Front Public Health,4: 222. https://doi.org/10.3389/fpubh.2016. 00222.

CSA and UNICEF Ethiopia (2018): Multidimensional Child Deprivation in Ethiopia. https://www.unicef.org/esa/sites/unicef.org.esa/files/2019-01/UNICEF-Ethiopia-2018-Multidimensional-Child-Deprivation.pdf

Dynes MM, Miller L, Sam T, Vandi MA, Tomczak B (2015). Perceptions of the Risk for Ebola and Health Facility Use Among Health Workers and Pregnant and Lactating Women - Kenema District, Sierra Leone, September 2014. Centers for Disease Control and Prevention Morbidity and Mortality Weekly Report (MMWR). 63: 51-52 https://www.cdc.gov/mmwr/preview $/ \mathrm{mmwrhtml} / \mathrm{mm} 6351 \mathrm{a3} . \mathrm{htm}$

Elston JW, Moosa AJ, Moses F, Walker G, Dotta N, Waldman J (2015). Impact of the Ebola outbreak on health systems and population health in Sierra Leone. J Public Health (Oxf). 38(4): 673-678. https://doi.org/10.1093/pubmed/fdv158.

Elston JWT, Cartwright C, Ndumbi P, Wright J (2017). The health impact of the 2014-15 Ebola outbreak. Public 
Health, 143: 60-70. https://doi.org/10.1016/j.puhe.2016.10.020.

Ethiopia Central Statistical Agency and ICF, mini Ethiopia Demographic and Health Survey (2019). Addis Ababa, Ethiopia, and Rockville, Maryland, USA.

Federal Ministry of Health of Ethiopia (2010). Health Sector Development Plan (HSDP) IV, 2010/11-2014/15. Addis Ababa, Ethiopia: Ministry of Health. http://www.nationalplanningcycles.org/sites/default/files/count ry_docs/Ethiopia/ethiopia_hsdp_iv_ final_draft_2010_-2015.pdf

Federal Ministry of Health of Ethiopia (2020).National Comprehensive COVID19 Management Handbook. FMOH, Ethiopia. First edition. APRIL 2020.https://covidlawlab.org/wpcontent/uploads/2020/o6/National Comprehensive-COVID19Management-Handbook.pdf

Kamara M, Najjemba R, van Griensven J, Yorpoi D, Jimissa AS, Chan AK, Mishra $S$ (2017). Increase in acute malnutrition in children following the 2014- 2015 Ebola outbreak in rural Sierra Leone. Public Health Action. 7(1): S27-S33. https://dx.doi.org/10.5588\%2Fpha.16.0084.

Lori JR, Rominski SD, Perosky JE, Munro ML, Williams G, Bell SA, Nyanplu AB, et al. (2015). A case series study on the effect of Ebola on facility-based deliveries in rural Liberia. BMC Pregnancy Childbirth, 15: 254. https://doi.org/10.1186/s12884-015-0694-x.

Roberton T, Carter ED, Chou VB, Stegmuller AR, Jackson BD, Tam Y, SawadogoLewis T, et al. (2020). Early estimates of the indirect effects of the COVID-19 pandemic on maternal and child mortality in low-income and middleincome countries: a modelling study.
Lancet Glob Health, 8: e901-08. https://doi.org/10.1016/S2214109X(20)30229-1.

Sochas L, Channon AA, Nam S (2017). Counting indirect crisis-related deaths in the context of a low-resilience health system: the case of maternal and neonatal health during the Ebola epidemic in Sierra Leone. Health Policy Plan, 32 (3): 32-39.

Somali Regional Health Bureau (2020). Somali Regional State Health Sector Transformation Plan II. (2019/20202029/2030 G.C

United Nations (2015). The Millennium Development Goals Report 2014, Ethiopia. Assessment of Ethiopia's progress towards the MDGs. Addis Ababa, Ethiopia. http://et.one.un.org/content/unct/ethiopia/en/home/ass istance-framework/millennium-development-goals. html.

United Nations (2020). "Policy Brief: The Impact of COVID-19 on Children". https://www.un.org/sites/un2.un.org/files/policy_brief_on_covid_imp act_on_children_16_april_2020.pdf.

VSO International (2015). Exploring the Impact of the Ebola Outbreak on Routine Maternal Health Services in Sierra Leone. Freetown, Sierra Leone and Liverpool, UK: VSO International, Liverpool School of Tropical Medicine. Wagenaar BH, Augusto O, Beste J, Toomay SJ, Wickett E, Dunbar N (2018). The 2014 - 2015 Ebola virus disease outbreak and primary healthcare delivery in Liberia: Time-series analyses for 2010-2016. PLoS Med. 15(2): e1002508. https://doi.org/10.1371/journal.pmed.1002508.

Wesseh CS, Najjemba R, Edwards JK, Owiti $\mathrm{P}$, Tweya H, Bhat P (2017). Did the Ebola outbreak disrupt immunisation services? A case study from Liberia. 
Oladeji et al./ COVID 19 Pandemic on the Utilization of Maternal Newborn and Child Health Services

Public Health Action,7(1): S82-S87. doi:10.5588/pha.16.0104

WHO (2020). Report of the WHO-China Joint Mission on coronavirus disease 2019 (COVID-19). https://www.who.- int/docs/default-source/coronaviruses/who-china-joint-mission-on-covid-19- final-report.pdf (accessed August13, 2020). 